\title{
PENGELOLAAN SARANA DAN PRASARANA SEKOLAH PADA PAUD NURUL MAGHFIRAH KOTA KENDARI
}

\author{
Wa Rosida ${ }^{1}$, Nurzaima ${ }^{2}$ \\ Program Study Administrasi Pendidikan, Universitas Muhammadiyah Kendari ${ }^{1}$ \\ Program Study Administrasi Pendidikan, Universitas Muhammadiyah Kendari ${ }^{2}$ \\ Email: warosida68@gmail.com
}

Received: December 11, 2020, reviewed December 20, 2020, published Apr 30, 2020

Citation: Wa Rosida, Nurzaima. (2020). Pengelolaan Sarana dan Prasarana Sekolah Pada Paud Nurul Maghfirah Kota Kendari. Edum Journal, 3(1)

\begin{abstract}
ABSTRAK
Sarana dan prasarana pendidikan juga menjadi salah satu tolak ukur dari mutu sekolah. Tetapi fakta di lapangan banyak ditemukan sarana dan prasarana yang tidak dioptimalkan dan dikelola dengan baik. Penelitian ini bertujuan untuk: (1) Mendeskripsikan pengelolaan sarana dan prasarana, dan (2) Mengetahui faktor-faktor yang mendukung dan menghambat pengelolaan sarana dan prasarana. Jenis penelitian ini merupakan penelitian deskriptif kualitatif yakni penelitian yang mengambarkan sekaligus mengkaji kondisi nyata obyek penelitian berdasarkan data-data autentik yang dikumpulkan. Subjek dalam penelitian ini adalah pengelola, guru dan operator di PAUD Nurul Maghfirah Kota Kendari. Teknik pengumpulan data dapat dilakukan dengan cara: Pertama, pengamatan yaitu peneliti mengamati kegiatan pihak sekolah dalam mengelola sarana dan prasarana. Kedua, wawancara, yakni melekukan tanya jawab langsung pada beberapa subjek penelitian untuk memperoleh data tentang Pengelolaan Sarana dan Prasarana di PAUD Nurul Maghfirah Kota Kendari, selanjutnya dianalisis secara deskriptif kualitatif. Hasil penelitian ini menunjukan bahwa yang pertama: bentuk pengelolaan sarana dan prasarana pembelajaran di PAUD Nurul Mahgfirah Kota Kendari yaitu perencanaan, pengadaan, inventarisasi, pemanfaatan dan pemeliharaan. Kedua, faktor pendukung yaitu adanya pemahaman tentang pengelolaaan sarana dan prasarana dan kemampuan mengelola. Sedangkan penghambat pengelolaan sarana dan prasarana yaitu lingkungan sekolah yang sering dilanda banjir dan kurangnya dukungan dari masyarakat sekitar sekolah.
\end{abstract}

Kata Kunci: Pengelolaan, Sarana dan Prasarana, PAUD

\section{ABSTRACT}

Managed school facilities can be one of the indications of school quality. However, the facts around schooling are found many facilities and infrastructure that are not optimized and managed properly. This study aims to: describe the management of facilities, and resolve the factors that support and hinder the management of facilities. This research is a qualitative descriptive study that is a study that both describes and examines the real condition of the research object based on authentic data collected. The subjects of this study are managers, teachers and operators in PAUD Nurul Maghfirah Kendari City. Data collection techniques were used observation and interviews. Then the data were analyzed descriptively qualitatively. The results of this study indicate that: Management of Learning Facilities and Infrastructure in PAUD Nurul Mahgfirah Kendari City includes planning, procurement, inventory, utilization and maintenance activities. Proper management of school facilities is supported by administrators with an understanding of the management of facilities and the ability to manage. The obstacles faced are: schools do not have guards and the geographical conditions of schools located in flood prone areas. In addition, the community around the school has not actively participated in maintaining

Keywords: School facility, Management, Early Chilhood Education 


\section{PENDAHULUAN}

Sarana dan prasarana pendidikan menjadi salah satu tolak ukur dari mutu sekolah. Tetapi fakta dilapangan banyak ditemukan sarana dan prasarana yang tidak dioptimalkan dan dikelola dengan baik untuk itu diperlukan pemahaman dan pengaplikasian manajemen sarana dan prasarana pendidikan persekolahan berbasis sekolah. Bagi pengambil kebijakan di sekolah pemahaman tentang sarana dan prasarana akan membantu memperluas wawasan tentang bagaimana ia dapat berperan dalam merencanakan, menggunakan dan mengevaluasi sarana dan prasarana yang ada sehingga dapat dimanfaatkan dengan optimal guna mencapai tujuan pendidikan.

Peraturan Pemerintah No. 19 Tahun 2005 tentang Standar nasional Pendidikan, pasal 1 ayat (8) mengemukakan standar sarana dan prasarana adalah Standar Nasional Pendidikan yang berkaitan kriteria minimal tentang ruang belajar, tempat olah raga, tempat beribadah, perpustakaan, laboratorium, bengkel kerja, tempat bermain, tempat berekreasi dan berkreasi, serta sumber belajar lain yang diperlukan untuk menunjang proses pembelajaran termasuk penggunaan teknologi informasi dan komunikasi. pada Bab VII Pasal 42 dengan tegas disebutkan bahwa; (1) Setiap satuan pendidikan wajib memiliki sarana yang meliputi perabot, peralatan pendidikan, media pendidikan, buku dan sumber belajar lainnya, bahan habis pakai, serta perlengkapan lain yang diperlukan untuk menunjang proses pembelajaran yang teratur dan berkelanjutan.

Menurut Tim Pakar Manajemen Pendidikan (2003:86) "pengelolaan sarana dan prasarana pendidikan dapat didefinisikan sebagai proses kerjasama pendayagunaan semua sarana dan prasarana pendidikan secara efektif dan efisien". Wahyuingrum (2000: 5), berpendapat bahwa sarana pendidikan adalah "segalah fasilitas yang diperlukakan dalam proses pembelajaran, yang dapat meliputi barang bergerak maupun barang yang tidak bergerak agar tujuan pendidikan tercapai". Menurut Ibrahim Bafadal (2003:2) bahwa "prasarana pendidikan adalah semua perangkat kelengkapan dasar yang tidak langsung menunjang pelaksanaan proses pendidikan di sekolah. Sedangkan Menurut Riduwan (2009), prasarana pendidikan dapat diartikan sebagai perangkat penunjang utama suatu proses atau usaha pendidikan agar tujuan pendidikan tercapai. Dari pendapat di atas diambil kesimpulan bahwa prasarana pendidikan adalah perangkat yang menunjang keberlangsungan proses pendidikan agar tujuan pendidikan tercapai.

Berdasarkan kamus Besar Bahasa Indonesia (1996:123), "sarana adalah segala sesuatu yang dapat digunakan sebagai alat dalam mencapai suatu maksud atau tujuan" Menurut E. Mulyasa, sarana pendidikan adalah peralatan dan perlengkapan yang secara langsung dipergunakan dan menunjang proses pendidikan, khususnya proses belajar, mengajar, seperti gedung, ruang kelas, meja kursi, serta alat-alat media pengajaran". Sedangkan pengertian prasarana berdasarkan kamus besar bahasa indonesia (1996:109) yaitu" segalah sesuatu yang merupakan penunjang utama terselenggaranya suatu proses".

Berdasarkan beberapa pendapat di atas dapat disimpulkan, bahwa sarana pendidikan adalah segala fasilitas bisa berupa peralatan, bahan dan perabot yang langsung di pergunakan dalam proses belajar di sekolah. Sedangkan prasarana pendidikan merupakan segalah sesuatu yang secara tidak langsung menunjang proses pendidikan.

Menurut Oteng (2001 :33) setiap sekolah memiliki prinsip-prinsip dan tata tertib mengenai penggunaan dan pemeliharaan sarana dan prasarana sekolah, hal itu bertujuan untuk mempermudah 
administrator dalam mengawasi dan mengatur sarana dan prasarana di sekolah tersebut

Sarana dan prasarana pendidikan pada dasarnya dapat dikelompokan dalam empat kelompok, yaitu tanah, bangunan, perlengkapan, dan perabot sekolah (side, building, equipment, and furniture). Agar semua fasilitas tersebut tersebut memberikan kontribusi yang berarti pada jalannya proses pendidikan, hendaknya dikelolah dengan baik. Pengelolaan yang dimaksud meliputi: (1) perencanaan, (2) pengadaan, penggunaan, (4) pemeliharan dan penghapusan.

Sarana dan prasaran pendidikan, khususnya lahan, bangunan dan pelengkapan sekolah menggambarkan program pendidikan atau kurikulum sekolah itu. Karena bangunan dan perlengkapan sekolah tersebut diadakan dengan berlandaskan pada kurikulum atau program pendidikan yang berlaku, sehingga dengan adanya kesesuaian itu memungkinkan fasilitas yang ada benarbenar menunjang jalanya proses ppendidikan. Pengelolaan bahan bangunan, dan perlengkapan sekolah merupakan tanggung jawab kepalah sekolah.

\section{METODE PENELITIAN}

Jenis penelitian ini merupakan penelitian deskriptif kualitatif yaitu penelitian yang mengambarkan sekaligus mengkaji kondisi nyata obyek penelitian berdasarkan data-data autentik yang dikumpulkan. Subjek dalam penelitian ini adalah Pengelolah, Tenaga Administrasi dan Guru di PAUD Nurul Maghfirah Kota Kendari. Teknik pengumpulan data dapat di tentukan dengan cara sebagai berikut : Pengamatan yaitu peneliti mengamati kegiatan pihak sekolah dalam mengelola sarana dan prasarana di PAUD Nurul Maghfirah Kota Kendari dan Wawancara, yakni melekukan tanya jawab langsung pada beberapa subjek penelitian untuk memperoleh data tentang Pengelolaan Sarana dan Prasarana di PAUD Nurul Maghfirah Kota Kendari. Tehnik analisis data adalah proses mencari dan menyusun secara sitematis data yang di peroleh dari hasil wawancara catatan lapangan dan cara mengorganisasikan sebuah data dalam sebuah kategori, menjabarkan, memilih mana yang penting dan membuat kesimpulan agar mempermudah diri sendiri atau orang lain.

\section{HASIL DAN PEMBAHASAN}

Pengelolaan Sarana dan Prasarana di PAUD Nurul Mahgfirah Kota Kendari dimulai dari perencanaan, pengadaan, inventarisasi, pemanfaatan dan pemeliharaan.

1. Perencanaan Perlengkapan PAUD Nurul Maghfirah

Adapun prosedur perencanaan perlengkapan pada PAUD Nurul Maghfirah dilakukan oleh pengelolah bersama guruguru, tugas guru melaporkan kepada pengelolah tentang sarana pembelajaran yang dibutuhkan kemudian pengelolah mempertimbangkan dengan keuangan sekolah, melalui kebutuhan sarana pembelajaran yang dilaporkan maka pihak sekolah melakukan perencanaan tentang sarana yang akan diadakan tentunya disesuaikan dengan keuangan sekolah. Pernyataan ini sesuai dengan hasil wawancara tentang prosedur perencanaan perlengkapan sekolah dengan pengelolah PAUD Nurul Maghfirah yang menyatakan bahwa :

Perencanaan perlengkapan sekolah dilakukan dengan melihat kebutuhan yang paling urjen melalui hasil musyawarah dengan guru-guru. Jadi untuk mengadakan sarana prasarana sekolah yang berupa perlengkapan sekolah sebelum diadakan terlebih dahulu direncanakan sesuai prosedur agar kelak perlengkapan yang akan diadakan sesuai kebutuhan sekolah sehingga tidak terkesan mubazir. 
2. Pengadaan Perlengkapan PAUD Nurul Maghfirah

Melalui hasil perencanaan yang matang pengadaan perlengkapan ditetapkan oleh pengelolah dan guru-guru. Setelah ada daftar kebutuhan perlengkapan pengelolah belanja sesuai kebutuhan yang disepakati bersama. Pernyataan ini sejalan dengan hasil wawancara dengan informan tentang pengadaan perlengkapan sekolah bahwa:

Kami selalu melihat kondisi sekolah, jika memang membutuhkan perlengkapan tambahan maka saya membuat perencanaan dan bersama-sama dengan guru untuk di adakannya perlengkapan sesuai kebutuhan, jika kondisi keuangan tidak memukinkan untuk pengadaan yang baru maka kami hanya memperbaiki yang rusak atau mencari bantuan dari luar.

\section{Inventarisasi Sarana dan Prasarana PAUD Nurul Maghfirah}

Adapun inventarisasi yang dilakukan pada PAUD Nurul Maghfirah adalah mencatat dan mendaftar barang-barang milik sekolah kedalam suatu daftar inventaris barang sacara tertib dan teratur. Kegunaan pancatatan barang-barang tersebut yakni untuk diketahui jumlah perlengkapan yang ada dan setiap sarana yang ada diberikan kode supaya tidak mudah hilang. Hal ini didukung dengan hasil wawancara dengan pengelola PAUD menyatakan bahwa:

Inventarisasi dilakukan dengan pencatatan atau pendaftaran barang-barang dalam daftar inventaris barang dan diberikan label pada setiap sarana yang ada. Tujuannya adalah untuk mengetahui banyaknya sarana dan prasarana serta dapat mempermudah pangawasan, meskipun perlengkapannya masih kurang karna keterbatasan anggaran.

\section{Pemanfaatan Sarana Prasarana PAUD Maghfirah \\ Sarana dan prasarana pada PAUD Nurul Maghfirah masih sangat terbatas,}

terutama ruang kegiatan belajar, dengan jumlah siswa 63 anak, ruang kegiatan belajar hanya dua kelas, tidak memiliki ruang pendidik dan tenaga kependidikan, lemari tempat arsip sekolah dan alat permainan edukatif sebagian besar rusak akibat terendam banjir. Untuk sementara ruang pendidik dan tenaga kependidikan memanfaatkan teras rumah disampig sekolah, yang mana rumah tersebut adalah rumah pemilik yayasan PAUD Nurul Maghfirah. Lahan sekolah yakni $400 \mathrm{~m} 2$ namun keterbatasan biaya untuk menamba gedung, baik untuk ruang kegiatan belajar maupun untuk ruang pendidik dan tenaga kependidikan. Keterangan ini sesuai dengan hasil wawancara dengan pengelolah yang menyatakan bahwa:

Sebagai pengelolah sangat berat untuk mengambil keputusan tentang pemanfaatan sarana dan prasarana yang ada, dikarenakan keterbatasan anggaran sehingga untuk penambahan sarana dan prasarana sebagai penunjang kegiatan bermain dan belajar sangat terbatas. Namun demi kalancaran belajar dan bermain sebagai kebutuhan anak PAUD di sini, kami memanfaatkan ruangan yang ada dengan alat permainan edukatif yang seadanya, untuk mengatasi keterbatasan kami menggunakan alat permainan edukatif yang terbuat dari bahan-bahan alam.

\section{Pemeliharaan Sarana Prasarana PAUD Nurul Maghfirah \\ Pemeliharaan sarana dan prasarana} dilakukan oleh pengelola PAUD, guru dan siswa, seperti kebersihan sekolah, perawatan cat gedung, pagar, penataan taman serta alat permainan setelah digunakan maka guru mengajak anak-anak untuk bersama-sama menyimpan atau membereskan mainan ketempat semula agar bisa digunakan jangka panjang, hal ini sejalan dengan pernyataan informan tentang pemeliharaan sarana dan prasarana sekolah yang menyatakan bahwa; 
Saya, guru dan siswa terlibat dalam pemeliharaan sarana dan prasarana, seperti alat permainan setelah digunakan maka guru mengajak anak-anak untuk bersama-sama menyimpan atau membereskan mainan ketempat semula agar bisa digunakan jangka panjang.

Berdasarkan hasil pengamatan langsung dan wawancara maka dapat diketahui bahwa pengelolaan sarana dan prasarana di PAUD Nurul Maghfirah terdapat lima aspek. Yang pertama, perencanaan sarana dan prasarana dilakukann melalui musyawarah untuk memutuskan perlengkapan apa yang dibutuhkan untuk diadakan. Kedua, pengadaan dilakukan dengan diajukan permohonan kepada yayasan untuk penambahan sarana pembelajaran. Ketiga inventarisasi yaitu kalau ada perlengkapan baru maka terlebih dahulu dilakukan pencantatan pada buku inventaris barang, supaya perlengkapan yang ada dapat dikenali. Keempat, pemanfaatan untuk mengantisipasi keterbatasanan sarana atau media pembelajaran guru-guru menggunakan bahan-bahan yang terdapat disekitar anak. Dan kelima, pemeliharaan dilakukan dengan menjaga semua perlangkapan agar bisa dipakai jangka panjang. Hal ini sejalan dengan pendapat Tim Pakar Manajemen Pendidikan (2003:86) bahwa pengelolaan sarana dan prasarana pendidikan dapat didefinisikan sebagai proses kerjasama pendayagunaan semua sarana dan prasarana pendidikan secara efektif dan efisien.

Pengelolaan sarana dan prasarana di PAUD Nurul Maghfirah banyak faktor yang mendukung dan menghambat. Adapun faktor-faktor yang menjadi pendukung dan menghambat dalam pengelolaan sarana dan prasarana di PAUD Nurul Maghfirah adalah sebagai berikut:

\section{Faktor-faktor yang Mendukung Pengelolaan Sarana dan Prasarana di PAUD Nurul Maghfirah}

1. Adanya Pemahaman Tentang

Pengelolaan Sarana Dan Prasarana

Adapun keterangan yang diperoleh dari pernyataan informan tentang pendistribusian sarana dan prasarana sekolah. Berdasarkan hasil wawancara dengan informan yang menyatakan pemahaman tentang pengelolaan sarana dan prasarana bahwa;

Kalau masalah sejauh mana pemahaman tentang pengelolaan sarana dan prasarana saya tentu tidak akan mampu mengukur diri sendiri namun, sejauh ini khususnya saya selaku pengelolah dan pada umumnya guru dan operator tentu berusaha meningkatkan pemahaman mengenai pengelolaan sarana dan prasarana sebab melalui pemahaman tersebut dapat membantu kami dalam memperluas wawasan tentang bagaimana dapat berperan dalam merencanakan, menggunakan, dan mengevaluasi prasarana dan sarana yang ada sehingga prasarana dan sarana tersebut dapat dimamfaatkan secara optimal untuk mencapai tujuan pendidikan”.

2. Adanya Menejemen Prasarana Dan Sarana Pendidikan

Adapun keterangan yang diperoleh dari pernyataan informan tentang manajemen sarana prasarana adalah;

Dengan diberlakukan otonomi daerah berarti pemerintah memberikan kesempatan kepada sekolah untuk berinisiatif dan berkarya sesuai dengan kamampuan lembaga untuk memanage sekolah masing-masing termasuk sarana dan prasarana. Dari pemahaman pengelolaan yang kami miliki sehingga dipengaturanya kami lakukan sesuai tahap-tahap atau sesuai prosedurnya".

Faktor-Faktor Yang Menghambat Pengelolaan Sarana Dan Prasarana pada PAUD Nurul Maghfirah

1. Lingkungan sekolah yang Sering dilanda banjir 
Berdasarkan hasil wawancara dengan pengelolah tentang sekolahnya yang sering dilanda banjir menyatakan bahwa:

Salah satu yang menghambat pengelolaan sarana dan prasarana di PAUD kami ini seringnya dilanda banjir, sehingga banyak sarana yang hanyut karena banjir, seperti lemari, alat permainan edukatif, bahkan arsip atau dokumen-dokumen sekolah.

2. Kurangnya dukungan dari masyarakat sekitar sekolah

Berdasarkan hasil wawancara dengan informan tentang pendapat mengenai dukungan dari masyarakat sekitar sekolah dalam hal pengelolaan sarana dan prasarana yang menyatakan bahwa;

Berdasarkan pengamatan kami selama ini ketika ada rapat dengan orang tua murid lalu kami menyampaikan untuk membantu dalam pengadaan penunjang belajar anak, orang tua tidak respek terhadap tawaran kami, karna kebanyakan orang tua murid di sini mata pencahariaanya sebagai buruh.

Berdasarkan hasil pengamatan lapangan dan wawancara maka dapat diketahui Faktor-faktor yang mendukung pengelolaan sarana dan prasarana pada PAUD Nurul Maghfirah yaitu adanya pemahaman tentang pengelolaan sarana dan prasarana dan adanya menejemen prasarana dan sarana pendidikan yang dimulai dari perencanaan, pengadaan, inventarisasi, pemanfaatan dan pemeliharaan. Sedangkan faktor-faktor yang menghambat pengelolaan sarana dan prasarana pada PAUD Nurul Maghfirah yaitu lingkungan sekolah yang sering dilanda banjir, kurangnya dukungan dari masyarakat sekitar sekolah. Begitupun dengan Peraturan Pemerintah No. 19 Tahun 2005 tentang Standar nasional Pendidikan, pasal 1 ayat (8) mengemukakan standar sarana dan prasarana adalah Standar Nasional Pendidikan yang berkaitan kriteria minimal tentang ruang belajar, tempat olah raga, tempat beribadah, perpustakaan, laboratorium, bengkel kerja, tempat bermain, tempat berekreasi dan berkreasi, serta sumber belajar lain yang diperlukan untuk menunjang proses pembelajaran termasuk penggunaan teknologi informasi dan komunikasi

\section{SIMPULAN}

Berdasarkan hasil penelitian maka kesimpulan pengelolaan sarana dan prasarana pada PAUD Nurul Maghfirah adalah sebagai berikut:

1. Bentuk pengelolaan sarana dan prasarananya yaitu merencanakan perlengkapan sekolah sesuai prosedur, mengadakan perlengkapan sekolah, inventarisasi sarana dan prasarana sekolah, memanfaatkan sarana dan prasarana secara kondusif, serta memelihara sarana dan prasarana dengan baik.

2. Faktor-faktor yang mendukung dan menghambat pengelolaan sarana dan prasarana pada PAUD Nurul Maghfirah adalah sebagai berikut;

a. Faktor-faktor yang mendukung pengelolaan sarana dan prasarana pada PAUD Nurul Maghfirah yaitu

1) Adanya pemahaman tentang pengelolaan sarana dan prasarana

2) Adanya menejemen prasarana dan sarana pendidikan

b. Faktor-faktor yang menghambat pengelolaan sarana dan prasarana pada PAUD Nurul Maghfirah yaitu

1) Lingkungan sekolah yang sering dilanda banjir

2) Kurangnya dukungan dari masyarakat sekitar sekolah

Berdasarkan pembahasan di atas, bahwa perlu adanya dukungan baik dari pengelola PAUD dan pemakai PAUD untuk memperbaiki dan menambahkan sarana prasarana supaya PAUD dapat berkembang.

UCAPAN TERIMAKASIH 
Ucapan Terimakasih kepada MENRISTEKDIKTI yang telah mendanai penelitian ini dan LPPM Universitas Muhammadiyah Kendari sebagai pengelola penelitian sehingga tim peneliti menyelesaikan penelitian ini tepat waktu dan insya Allah tepat guna.

\section{DAFTAR PUSTAKA}

Anwar, Moch. Idoch. 2004. Administrasi Pendidikan dan Menajemen Biaya Pendidikan. Bandung: CV Alpabeta.

Arikunto, Suharsimi. 1993. Organisasi dan Administrasi Pendidikan Teknologi dan Kejuruan. Yogyakarta: Grafindo Persada.

Burhanuddin. 1994. Analisis Administrasi Menejemen dan Kepemimpinan pendidikan. Jakarta: Bumi Aksara.

Buhanuddin, Yusak. 1990. Administrasi Pendidikan. Bandung: CV Pustaka setia.

Bafadal, Ibrahi. 2003. Menejemen Perlengkapan Sekolah dan Aplikasinya. Jakarta: Bumi Aksara.

Cardoso, Fausitisno. 2001. Menejemen Sumber Daya Manusia dan Kepemimpinan Pendidikan. Jakarta: Bumi Aksara.

Daryanto, M. 2005. Administrasi Pendidikan. Jakarta: Rineka Cipta.

Depdikbud. 1996. Kamus Besar Bahasa Indonesa. Jakarta: Balai Pustaka.

Douglas, Hart R. 1963. Modern Administration of Secondary. Boston: Ginn \& Company.

Mulyasa, E,. 2002. Menejemen Berbasis Sekolah Konsep, Strategi, dan Implementasi. Bandung: PT Remaja Rosdakarya.

Peter dan Salim Yeni. 1991. Campus bahasa Indonesa Komteporer. Jakarta: Modern English Press.

Pidarta, Made. 2004. Manajemen Pendidikan Indonesia. Jakarta: PT. Rineka Cipta.
Purwanto Ngalim. 1987. Administrasi dan Supervisi Pendidikan. Bandung: PT Remaja Rosdakarya.

Ridoune. 2009. Menejemen Sarana dan Prasarana Pendidikan Islam, (online) http://ridoune co $\mathrm{hr} \mathrm{htm}$, diakes 15 februari pukul 5:00 pm

Sabri, Aliyusuf. 2005. Pengantar Ilmu Pendidikan. Jakarta: UIN Jakarta Press.

Sagala, Syaiful. 2009. Konsep dan Makna Pembelajaran. Bandung: Alfabeta

Soerjan. 1988. Sarana dan Prasarana. Jaklarta: Bumi Aksara

Sugiono. 2007. Metode penelitian kualitatif kuantitatif dan $R$ \& $D$. Bandung: Alfabeta.

Tahalele, J.F\& dan Soekarno Indrafacrudi. 1975. Kepemimpinan pendidikan. Malang: Sub Proyek Buku Pelajaran P3T, IKIP Malang.

Wahyuningrum. 2000. Buku Ajar Menejemen Fasilitas Pendidikan. Yogyakarta: FIP. 